\title{
COVID-19 Repurposed Therapeutics Targeting the Viral Protease and Spike-protein:ACE2 Interface using MD-based Pharmacophore and Consensus Virtual Screening
}

\author{
Brady D. Garabato, ${ }^{*}$ Federico Falchi, ${ }^{2}$ and Andrea Cavalli ${ }^{3}$ \\ ${ }^{1,3}$ Italian Institute of Technology, Via Enrico Melen, 83, 16152 Genova GE, Italy \\ ${ }^{2}$ Molecular Horizon srl, Via Montelino, 30, 06084, Bettona PG, Italy
}

\begin{abstract}
Molecular dynamics (MD) and enhanced sampling MD was performed for $100 \mathrm{~ns}$ on the biological assembly of the COVID-19 protease (6LU7), and a template of the COVID-19 S-protein:ACE2 receptor interface $(99.88 \%$ coverage of 6M0J; model03 swissmodel). Apo-site pharmacophores of the resulting structural clusters were used to mine the FDA database ( 8700 compounds), and a multi-target library was developed from MD-based hits in high affinity sites across $100 \mathrm{~ns}$. Consensus hits from high throughput docking in crystal structures 5R82, 6LU7 and 6Y2F (protease), and 6VW1 (S-protein:ACE2) were also added, and the resulting libraries were re-docked into MD sites to collect potential COVID-19 re-purposed therapeutics by estimated binding energies.
\end{abstract}

One sentence summary: Potential COVID-19 repurposed therapeutics targeting the viral protease and the S-protein: ACE2 interface are collected based on molecular dynamics, pharmacophore-based data mining, and consensus-based computational docking.

\section{Introduction}

Severe acute respiratory syndrome coronavirus 2 (SARS-CoV-2)-associated coronavirus disease 2019 (COVID-19) is a global pandemic challenging our economy and healthcare infrastructures. From the first reported cases in Wuhan China in December 2019, significant research has been put forth to both understand and treat the disease, for which there remains no known cure. ${ }^{1-5}$ Strategies for the treatment of COVID-19 can be divided into two areas; those targeting viral replication leading to severe symptoms and respiratory failure, and those targeting initiation of the infection. Due to the rapid onset of the pandemic, and the long timeframes of drug and vaccine development, the need for immediate treatments has made repurposing current therapeutics a necessary option.

Here we report preliminary computational results of our current research that includes experimental validation and extended virtual screening on longer MD time-scales $(>\mu \mathrm{s})$ and other COVID-19 protein targets. Although this work is ongoing, due to urgency we feel initial results warrant release to the experimental community. In this study we report approved and investigational therapeutics with high affinities towards sites in the COVID-19 viral protease (Table 1) and S-protein:ACE2 interface (Table 2), as well other compounds with favorable interactions (SI) based on molecular dynamics (MD) and consensus high throughput virtual screening.

\section{Methods}

MD simulations were carried out for 80 ns on both systems using the Gromacs 2018.3 package. $^{6}$ Simulations were run in the NPT ensemble, using the Parrinello-Rahman barostat with time constant $\tau=2 \mathrm{ps}$ and the V-rescale thermostat with time constant $\tau=0.1 \mathrm{ps}$, and a time step of $\mathrm{dt}=2 \mathrm{fs} .{ }^{7,8}$ Minimizations were performed on the initial protein structures up to a force threshold of $10 \mathrm{kj} \mathrm{mol}^{-1} \AA^{-1}$, and the resulting geometries were brought from 0 to $300 \mathrm{~K}$ using a constant annealing of $400 \mathrm{ps}$. In the case of the S-protein:ACE2 interface, enhanced sampling was carried out using Plumed version 2018.3 in Gromacs for N-acetly glucosamine (NAG) ${ }^{9}$ where the ligand-protein interaction was left un-biased, and NAG experiences a slight restraining potential $5 \AA$ outside of the initial bound state (S1). This both prevents escape and allows sampling of detachment events without biasing ligand desorption. NAG was parameterized as a single point gas-phase Hartree-Fock calculation with NWChem, and the derived charges were embedded using the RESP method in antechamber and Biki 1.3. ${ }^{10}$

Initial binding sites were identified for both systems using Ligand Scout 4.4, ${ }^{11}$ at $1 \mathrm{~ns}, 40 \mathrm{~ns}$, and $80 \mathrm{~ns}$ from average structures of the most clustered conformations in corresponding $5 \mathrm{~ns}$ windows. Apo-site pharmacophores including exclusion volumes were constructed using Ligand Scout 4.4, and the FDA database from Drug Bank was converted to pharmacophore features and mined for spatial similarity. High scoring hits on the database ( $>65$ similarity) were collected for each site and docked, and low energy conformations were merged with apo-site pharmacophores to remine the database for possible missed hits. Docking was performed using Autodock 4.2 with 70 genetic algorithm runs, an RMSD cluster tolerance of $1.7 \AA$, with 200 population individuals, and the maximum number of energy evaluations set to $5 \times 10^{6}$, with to $7 \times 10^{4}$ generations. ${ }^{5}$ The resulting concatenated libraries consisted of 91 ligands 
for the protease, and 128 ligands for the S-protein:ACE2 interface. Hits from consensus-based VS were further added (S7), and included Amprenavir, Nelfinavir, Sofosbuvir, and Tenofovir for the protease. Approved or investigational ligands with at least $-20 \mathrm{kcal} / \mathrm{mol}$ estimated binding energies (Tables 1,2) were separated from those with favorable interactions lower than $-15 \mathrm{kcal} / \mathrm{mol}(\mathrm{SI})$.

\section{Results}

Current effective treatments targeting viral replication and associated severe symptoms include Chloroquine and Hydroxychloroquine, Hydroxychloroquine with Azithromycin, Remdesivir, and in some cases janus-associated kinase inhibitors such as Ruxolitinib. ${ }^{12-18}$ Antivirals such as Ganciclovir, Acyclovir, and Ribavarin have in contrast been declared inactive for COVID-19, and known viral protease inhibitors such as Darunavir (S5) and the pro-drug system Lopinavir-Ritonavir have also shown no significant antiviral activity, which in some sense was confirmed in this study- Lopinavir was not significant in consensus VS, and has low symmetric site affinity at 80 ns. ${ }^{19-22}$ The HIV antivirals Sofosbuvir, Nelfinavir, and Amprenavir were blind pharmacophore-based hits as well as consensus-based VS hits, and are shown in Figure 1. Alternate hits in their lowest energy binding modes, along with protein clusters are further collected in the SI.

Although site 1 of the inhibited protease is the most logical drug target from crystal structure, the biological mechanism leading to the inhibited state remains unclear. Based on binding affinities at the hetero-dimer interface, and also the symmetric inhibition site 3 , it is possible that inhibitor pre-binding occurs before binding in site $1 / 3$, or that protein response causes changes in symmetric site binding, or that overall efficacy is somehow related to perturbing the heterodimer interface. This virtual screening attempts to overcome such variables in protein response by probing multi-site affinity from the crystal-based biologically active form, to a relaxed state to $100 \mathrm{~ns}$. For example, Atorvastatin has high binding affinity towards site 1 at $1 \mathrm{~ns}$, while Sofosbuvir shows binding preference towards the hetero-dimer interface at site 2. At $40 \mathrm{~ns}$ Sofosbuvir still shows preference to the hetero-dimer interface, like the other compounds, with Nelfinavir at the highest affinity to symmetric site 3. It is not until $80 \mathrm{~ns}$ in the relaxed state that Sofosbuvir shows direct preference towards site 1 . On the other hand, Lopinavir shows preference to site 1 vs. the heterodimer interface at $1 \mathrm{~ns}$, and $40 \mathrm{~ns}$, similar to Fexofenadine, but has low affinity for the symmetric site 3 in the relaxed 80 ns state. There seem to be two chemotype trends in this regard, but we report affinity here across all sites.

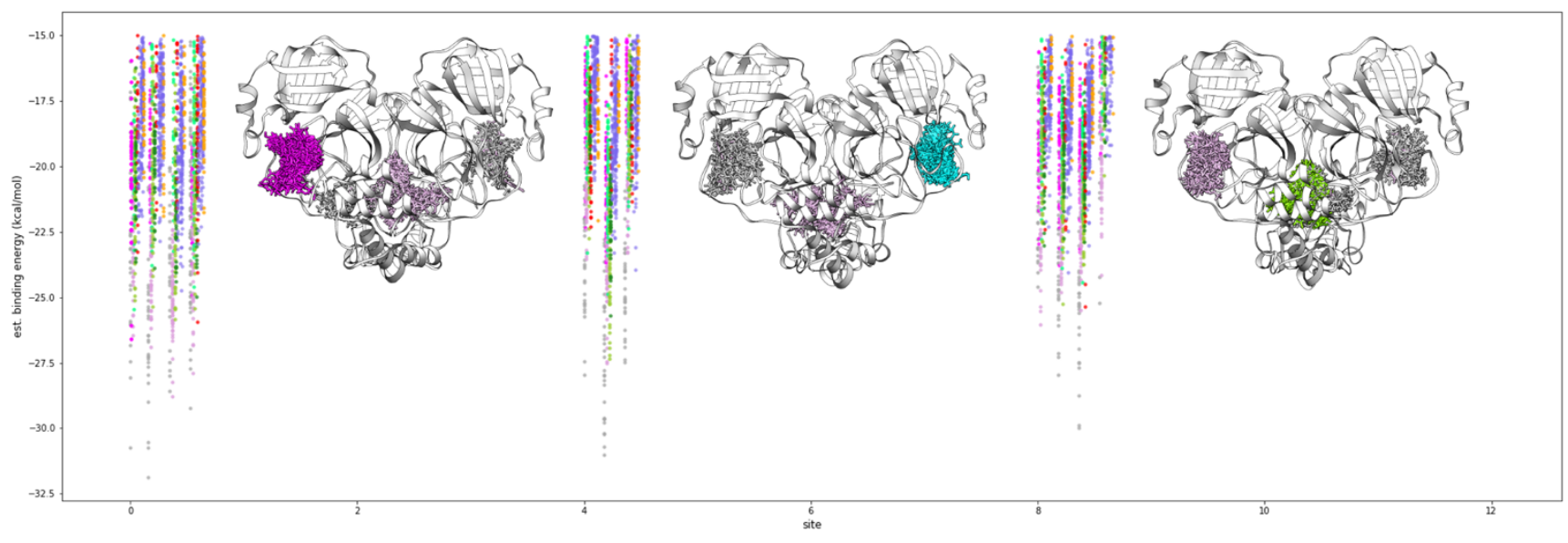

\begin{tabular}{|c|c|c|c|c|c|c|c|c|c|c|c|c|c|}
\hline \multirow[t]{3}{*}{ Compound } & \multicolumn{11}{|c|}{ est. binding energy (kcal/mol); time(ns); site } & \multirow{3}{*}{$\begin{array}{l}\text { Database } \\
\text { ID }\end{array}$} & \multirow[t]{3}{*}{ Status } \\
\hline & \multicolumn{4}{|c|}{$1 \mathrm{~ns}$} & \multicolumn{3}{|l|}{$40 \mathrm{~ns}$} & \multicolumn{4}{|l|}{$80 \mathrm{~ns}$} & & \\
\hline & 1 & $1 a$ & 2 & 3 & 1 & 2 & 3 & 1 & $2 a$ & $2 \mathrm{~b}$ & 3 & & \\
\hline BA3 & -30.7 & -31.9 & -28.6 & -29.2 & -28.0 & -31.0 & -27.5 & -24.6 & -28.0 & -30.0 & -25.2 & DB01690 & exp.; nucleotide \\
\hline Atorvastatin & -26.6 & -22.1 & -25.7 & -24.9 & -22.3 & -23.7 & -18.7 & -22.9 & -23.8 & -23.3 & -19.6 & $\underline{\mathrm{DB} 01076}$ & approved \\
\hline Sofosbuvir & -26.5 & -26.9 & -28.8 & -27.9 & -23.5 & -27.5 & -23.3 & -26.1 & -24.8 & -25.5 & -24.1 & DB08934 & approved \\
\hline Nelfinavir & -25.4 & -23.8 & -23.2 & -24.6 & -23.3 & -24.9 & -23.4 & -22.7 & -23.9 & -24.4 & -20.3 & DB00220 & approved \\
\hline Montelukast & -25.1 & -25.3 & -25.8 & -25.4 & -22.7 & -27.3 & -21.1 & -23.5 & -25.2 & -23.7 & -20.4 & DB00471 & approved \\
\hline Fexofenadine & -23.6 & -23.9 & -24.4 & -25.0 & -20.8 & -25.7 & -20.7 & -23.0 & -22.7 & -22.9 & -19.6 & DB00950 & approved \\
\hline Riboflavin & -22.9 & -20.8 & -24.1 & -22.9 & -19.2 & -22.6 & -20.7 & -21.6 & -22.0 & -21.6 & -19.6 & DB03247 & approved \\
\hline Sultamicillin & -21.9 & -21.5 & -24.7 & -21.6 & -19.4 & -21.9 & -20.8 & -21.1 & -21.6 & -20.4 & -17.7 & DB12127 & approved \\
\hline Eluxadoline & -21.8 & -22.8 & -23.7 & -22.3 & -20.5 & -22.7 & -23.9 & -22.3 & -24.0 & -23.0 & -19.6 & DB09272 & approved \\
\hline Relugolix & -21.7 & -22.1 & -20.2 & -21.3 & -20.3 & -23.3 & -21.7 & -19.7 & -23.2 & -20.2 & -18.3 & DB11853 & investigational \\
\hline Macimorelin & -20.1 & -19.9 & -23.8 & -20.8 & -18.2 & -19.4 & -19.2 & -18.7 & -20.1 & -19.1 & -19.2 & DB13074 & approved \\
\hline Amprenavir & -20.4 & -21.9 & -19.3 & -21.8 & -18.2 & -20.0 & -20.2 & -18.9 & $\begin{array}{l}-19.8 \\
\end{array}$ & -20.2 & -18.0 & DB00701 & approved \\
\hline
\end{tabular}

Figure 1. Re-docking scores in estimated kcal/mol (Autodock 4.2) of pharmacophore hits on the FDA database from 80 ns MD of the biologically active Cov19 protease. The lowest energy poses of each ligand are shown in their binding sites and colored uniformly to the ligand with the lowest binding energy. Site clusters are shown in grey when the lowest affinities are shared across sites for one ligand. Energies of the di-nucleotide analog BA3 are shown in grey. 
Human infections by SARS coronaviruses are closely associated with interactions between the viral spike protein and human receptors, namely the Angiotensin-converting enzyme 2 (ACE2). ${ }^{23-28}$ Virtual screening based on high throughput docking combined with MD was previously carried out on the ZINC database, ${ }^{29}$ and the highest ranked hits from that study are included herein, along with corresponding highest ranked hits from MD-based pharmacophore virtual screening shown in Figure 2, notable high affinity biomolecule analogs in grey, and other significant binding modes are collected in the SI. The main difference between the two approaches is an additional layer of chemical abstraction from structure that enriches the virtual screening.

Three sites were observed at 1 ns near the crystal structure; luminal sites 1a, and 3, and site 2 at the S-protein:ACE2 interface, where Montelukast had the highest affinity. At $40 \mathrm{~ns}$, both affinity and re-docked pharmacophore hits increased for sites 1a, 2, and 3, and an additional site denoted $2 \mathrm{t}$ emerged within the S-protein at the interface, where binding energies were determined by re-docking into the unbound S-protein. The distinction between sites 2 and $2 \mathrm{t}$ account for possible inhibition of the unbound S-protein (2t), or affinity towards site 2 in the S-protein:ACE2 interface leading to a ligand-S-protein $2 \mathrm{t}$ state. At $80 \mathrm{~ns}$ a site emerges denoted site 1 near the S-protein loop, showing the highest ligand binding affinity, with Fexofenadine as the most associated approved compound. Both Fexofenadine and Montelukast show high S-protein affinity at all sites screened in the relaxed state, with Fexofenadine highest at sites 1 and 2, and Montelukast highest at sites $2 \mathrm{t}$ and 3 .

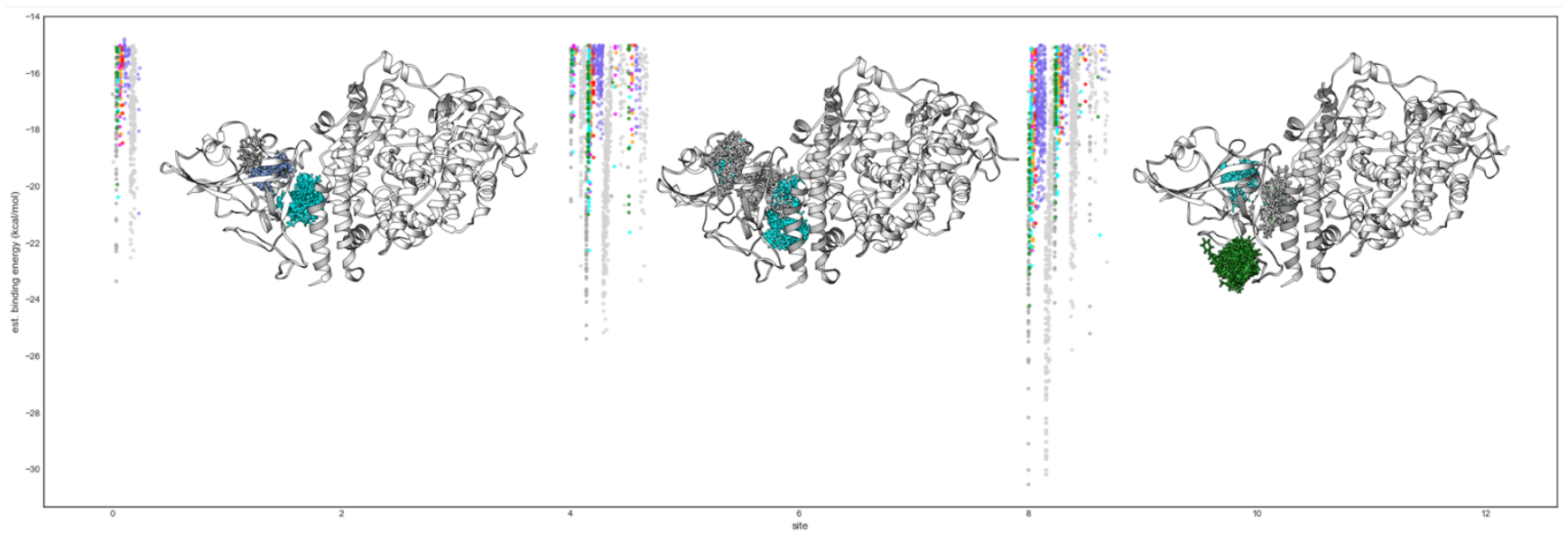

\begin{tabular}{|c|c|c|c|c|c|c|c|c|c|c|c|c|c|}
\hline \multirow[t]{3}{*}{ Compound } & \multicolumn{11}{|c|}{ est. binding energy (kcal/mol); time(ns); site } & \multirow{3}{*}{$\begin{array}{l}\text { Database } \\
\text { ID }\end{array}$} & \multirow[t]{3}{*}{ Status } \\
\hline & \multicolumn{3}{|c|}{$1 \mathrm{~ns}$} & \multicolumn{4}{|c|}{$40 \mathrm{~ns}$} & \multicolumn{4}{|l|}{$80 \mathrm{~ns}$} & & \\
\hline & 1a & 2 & 3 & $1 \mathrm{a}$ & 2 & $2 \mathrm{t}$ & 3 & 1 & 2 & $2 \mathrm{t}$ & 3 & & \\
\hline $\mathrm{NADH}^{*}$ & -16.7 & -23.4 & -- & -20.5 & -25.4 & -20.6 & -19.3 & -30.5 & -24.1 & -18.5 & -- & DB00157 & nutraceutical \\
\hline Fexofenadine & -- & -19.9 & -- & -17.6 & -20.1 & -16.3 & -20.9 & -24.2 & -21.1 & -17.1 & -17.5 & DB00950 & approved \\
\hline Montelukast & -- & -20.4 & -- & -18.8 & -22.3 & -19.3 & -21.6 & -22.8 & -20.3 & -17.4 & -21.7 & DB00471 & approved \\
\hline Cefpiramide & -- & -18.5 & -- & -17.5 & -20.2 & -17.4 & -18.0 & -22.6 & -18.8 & -15.3 & -- & $\underline{\mathrm{DB} 00430}$ & approved \\
\hline Etalocib & -- & $\begin{array}{ll}-18.1 \\
\end{array}$ & -- & $\begin{array}{l}-15.7 \\
\end{array}$ & -18.2 & $\begin{array}{ll}-16.4 \\
\end{array}$ & -- & -22.1 & -18.4 & $\begin{array}{ll}-15.4 \\
\end{array}$ & -15.2 & DB12850 & investigational \\
\hline Chenodeoxycholic acid & -- & -16.5 & -- & -- & -16.6 & -- & -17.3 & -21.4 & -17.4 & -15.0 & -- & $\overline{\text { DB06777 }}$ & approved \\
\hline Lumacaftor & -- & -17.8 & -- & -- & -16.0 & -15.9 & -18.1 & -20.8 & -17.9 & -15.8 & -- & $\underline{\mathrm{DB} 09280}$ & approved \\
\hline Cloxacillin & -- & -- & -16.0 & -- & -15.1 & -- & -17.9 & -20.7 & -- & -- & -16.2 & DB01147 & approved \\
\hline Foretenib & -- & -17.1 & $\begin{array}{ll}-- \\
\end{array}$ & -- & -17.9 & -- & -- & -20.7 & -18.1 & -- & -- & DB12307 & investigational \\
\hline Cholic Acid & -- & -- & -- & -- & -16.3 & $\begin{array}{ll}-15.1 \\
\end{array}$ & -- & -20.5 & -- & -15.2 & -- & DB02659 & approved \\
\hline Travoprost & -- & -16.0 & -- & $\begin{array}{ll}- \\
-\end{array}$ & -17.8 & -15.7 & -15.9 & -20.5 & -17.8 & $\begin{array}{ll}- \\
\end{array}$ & -15.8 & DB00287 & approved \\
\hline Dexamethasone MSB & -- & -16.8 & -- & -15.1 & -18.3 & -- & -- & -20.4 & -18.5 & -- & -- & $\overline{\text { DB14703 }}$ & approved; exp \\
\hline Rosuvastatin & -- & -18.1 & -- & -15.2 & -17.4 & -- & 17.8 & -20.4 & -16.0 & -15.7 & -15.8 & DB01098 & approved \\
\hline Telotristat ethyl & -- & -17.2 & -- & -15.7 & -18.1 & -- & -- & -20.3 & -- & -- & -- & DB12095 & app;investigational \\
\hline \multicolumn{14}{|l|}{ * } \\
\hline AP-22408 & -- & -21.6 & -- & -19.0 & -24.7 & -18.8 & -18.9 & -26.9 & -25.8 & -17.6 & -- & DB01830 & exp; Phe peptide \\
\hline RU83876 & -- & -22.2 & -- & -19.5 & -25.1 & -16.3 & -20.9 & -26.9 & -24.3 & -17.7 & -- & DB02336 & exp; dipeptide \\
\hline ATP & -15.6 & -21.1 & -20.9 & -18.6 & -22.1 & -- & -22.8 & -26.9 & -- & -19.2 & -18.8 & DB00171 & nutraceutical \\
\hline RU81843 & -- & -- & -- & -17.2 & -22.6 & -16.3 & 20.2 & -26.1 & -21.1 & -17.1 & -17.7 & $\overline{\text { DB04495 }}$ & exp; dipeptide \\
\hline FNS & -- & -18.6 & -15.8 & -- & -20.3 & -16.4 & -18.4 & -18.4 & -19.3 & -17.0 & -22.7 & DB02164 & exp; nucleotide \\
\hline Vitamin E & -- & -20.1 & -- & -- & -18.4 & -15.7 & -17.5 & $\begin{array}{ll}-- \\
-\end{array}$ & -19.5 & -- & -- & DB00163 & nutraceutical \\
\hline ZINC000003869685 & -- & $\begin{array}{ll}- \\
--\end{array}$ & -- & -- & -- & -- & -- & 17.2 & -- & -- & -- & & \\
\hline ZINC000018185774 & -- & -- & -- & -- & -- & -- & -- & -- & -- & -- & -15.9 & & \\
\hline
\end{tabular}

Figure 2. Re-docking scores in estimated kcal/mol (Autodock 4.2) of pharmacophore hits on the FDA database from 80 ns MD of the Cov-19 S-protein:ACE2 interface. The lowest energy poses of each ligand are shown in their binding sites and colored uniformly to the ligand with the lowest binding energy. Site clusters are shown in grey when the lowest affinities are shared across sites for one ligand. Energies of significant biomolecule analogs are shown in grey. 


\section{Conclusions}

Based on the biologically active form of the COVID-19 protease from the 6LU7 crystal structure, ${ }^{30}$ and a model of the COVID-19 S-protein:ACE2 interface from 6M0J, ${ }^{31}$ MD-based apo-site pharmacophore and consensus-based (6LU7, 5R82, 6Y2F) VS was used to screen the FDA database of 8700 compounds to propose a multi-target library with high affinities towards their associated dynamic targets by computational docking. Notable compounds include selected HIV protease inhibitors, cancer and hepatitis targeting compounds, a lipid lowering drug (Atorvastatin), a leukotriene receptor agonist (Montelukast), an antihistamine (Fexofenadine), and other nutraceuticals and biomolecule analogs. Although inhibition mechanisms are not explicitly proposed based on this approach, energetic and biological detail was nevertheless added by MD and enhanced sampling to enrich the virtual screening. Further experimental and in-silico validation is ongoing and includes other protein targets, but we nevertheless disclose preliminary results here in hope to identify active chemotypes against COVID-19 infection and replication.

\section{Acknowledgements}

We would like to thank and acknowledge the CINECA computational center for providing HPC resources.

\section{Competing interest}

No competing interests are declared.

*Corresponding author: brady.garabato@iit.it

\section{References}

1. Qiu-Hua Li, Y.-H. M., Ning Wang, Ying Hu, Zhao-Zhe Liu, New Coronavirus-Infected Pneumonia Engulfs Wuhan. Asian Toxicology Research 2020, 2 (1), 1-7.

2. Xu, X.; Chen, P.; Wang, J.; Feng, J.; Zhou, H.; Li, X.; Zhong, W.; Hao, P., Evolution of the novel coronavirus from the ongoing Wuhan outbreak and modeling of its spike protein for risk of human transmission. Science China Life Sciences 2020, 63 (3), $457-460$.

3. Guarner, J., Three Emerging Coronaviruses in Two Decades: The Story of SARS, MERS, and Now COVID-19. American Journal of Clinical Pathology 2020, 153 (4), 420-421.

4. Wu, F.; Zhao, S.; Yu, B.; Chen, Y. M.; Wang, W.; Song, Z. G.; Hu, Y.; Tao, Z. W.; Tian, J. H.; Pei, Y. Y.; Yuan, M. L.; Zhang, Y. L.; Dai, F. H.; Liu, Y.; Wang, Q. M.; Zheng, J. J.; Xu, L.; Holmes, E. C.; Zhang, Y. Z., A new coronavirus associated with human respiratory disease in China. Nature 2020, 579 (7798), 265-269.

5. Wu, F.; Zhao, S.; Yu, B.; Chen, Y.-M.; Wang, W.; Song, Z.-G.; Hu, Y.; Tao, Z.-W.; Tian, J.-H.; Pei, Y.-Y.; Yuan, M.-L.; Zhang, Y.-L.; Dai, F.-H.; Liu, Y.; Wang, Q.-M.; Zheng, J.-J.; Xu, L.; Holmes, E. C.; Zhang, Y.-Z., A new coronavirus associated with human respiratory disease in China. Nature 2020, 579 (7798), 265-269.

6. Abraham, M. J.; Murtola, T.; Schulz, R.; Páll, S.; Smith, J. C.; Hess, B.; Lindahl, E., GROMACS: High performance molecular simulations through multi-level parallelism from laptops to supercomputers. SoftwareX 2015, 1-2, 19-25.

7. Parrinello, M.; Rahman, A., Polymorphic transitions in single crystals: A new molecular dynamics method. J. Appl. Phys. 1981, 52, 7182.

8. $\quad$ Bussi, G.; Donadio, D.; Parrinello, M., Canonical sampling through velocity rescaling. J. Chem. Phys. 2007, $126,014101$.

9. Bonomi, M.; Branduardi, D.; Bussi, G.; Camilloni, C.; Provasi, D.; Raiteri, P.; Donadio, D.; Marinelli, F.; Pietrucci, F.; Broglia, R. A.; Parrinello, M., PLUMED: A portable plugin for free-energy calculations with molecular dynamics. Comput. Phys. Commun. 2009, $180,1961$.

10. Decherchi, S.; Bottegoni, G.; Spitaleri, A.; Rocchia, W.; Cavalli, A., BiKi Life Sciences: A New Suite for Molecular Dynamics and Related Methods in Drug Discovery. Journal of Chemical Information and Modeling 2018, 58 (2), 219-224.

11. Wolber, G.; Langer, T., LigandScout: 3-D Pharmacophores Derived from Protein-Bound Ligands and Their Use as Virtual Screening Filters. Journal of Chemical Information and Modeling 2005, 45 (1), 160-169.

12. Siddiqi, H. K.; Mehra, M. R., COVID-19 Illness in Native and Immunosuppressed States: A Clinical-Therapeutic Staging Proposal. The Journal of Heart and Lung Transplantation 2020.

13. Gautret, P.; Lagier, J.-C.; Parola, P.; Hoang, V. T.; Meddeb, L.; Mailhe, M.; Doudier, B.; Courjon, J.; Giordanengo, V.; Vieira, V. E.; Dupont, H. T.; Honoré, S.; Colson, P.; Chabrière, E.; La Scola, B.; Rolain, J.-M.; Brouqui, P.; Raoult, D., Hydroxychloroquine and azithromycin as a treatment of COVID-19: results of an open-label non-randomized clinical trial. International Journal of Antimicrobial Agents 2020, 105949.

14. Liu, J.; Cao, R.; Xu, M.; Wang, X.; Zhang, H.; Hu, H.; Li, Y.; Hu, Z.; Zhong, W.; Wang, M., Hydroxychloroquine, a less toxic derivative of chloroquine, is effective in inhibiting SARS-CoV-2 infection in vitro. Cell Discovery 2020, 6 (1), 16.

15. Gao, J.; Tian, Z.; Yang, X., Breakthrough: Chloroquine phosphate has shown apparent efficacy in treatment of COVID-19 associated pneumonia in clinical studies. BioScience Trends 2020, 14 (1), $72-73$.

16. Stebbing, J.; Phelan, A.; Griffin, I.; Tucker, C.; Oechsle, O.; Smith, D.; Richardson, P., COVID-19: combining antiviral and antiinflammatory treatments. The Lancet Infectious Diseases 2020, 20 (4), 400-402.

17. Lanini, S.; Ioannidis, J. P. A.; Vairo, F.; Pletschette, M.; Portella, G.; Di Bari, V.; Mammone, A.; Pisapia, R.; Merler, S.; Nguhuni, B.; Langer, M.; Di Caro, A.; Edwards, S. J. L.; Petrosillo, N.; Zumla, A.; Ippolito, G., Non-inferiority versus superiority trial design for new antibiotics in an era of high antimicrobial resistance: the case for post-marketing, adaptive randomised controlled trials. The Lancet Infectious Diseases 2019, 19 (12), e444-e451. 
18. Wang, M.; Cao, R.; Zhang, L.; Yang, X.; Liu, J.; Xu, M.; Shi, Z.; Hu, Z.; Zhong, W.; Xiao, G., Remdesivir and chloroquine effectively inhibit the recently emerged novel coronavirus (2019-nCoV) in vitro. Cell Research 2020, 30 (3), 269-271.

19. Wang, D.; Hu, B.; Hu, C.; Zhu, F.; Liu, X.; Zhang, J.; Wang, B.; Xiang, H.; Cheng, Z.; Xiong, Y.; Zhao, Y.; Li, Y.; Wang, X.; Peng, Z., Clinical Characteristics of 138 Hospitalized Patients With 2019 Novel Coronavirus-Infected Pneumonia in Wuhan, China. JAMA 2020, 323 (11), 1061-1069.

20. Li, H.; Wang, Y. M.; Xu, J. Y.; Cao, B., [Potential antiviral therapeutics for 2019 Novel Coronavirus]. Zhonghua jie he he hu xi za zhi $=$ Zhonghua jiehe he huxi zazhi $=$ Chinese journal of tuberculosis and respiratory diseases 2020, 43 (0), E002-E002.

21. Cao, B.; Wang, Y.; Wen, D.; Liu, W.; Wang, J.; Fan, G.; Ruan, L.; Song, B.; Cai, Y.; Wei, M.; Li, X.; Xia, J.; Chen, N.; Xiang, J.; Yu, T.; Bai, T.; Xie, X.; Zhang, L.; Li, C.; Yuan, Y.; Chen, H.; Li, H.; Huang, H.; Tu, S.; Gong, F.; Liu, Y.; Wei, Y.; Dong, C.; Zhou, F.; Gu, X.; Xu, J.; Liu, Z.; Zhang, Y.; Li, H.; Shang, L.; Wang, K.; Li, K.; Zhou, X.; Dong, X.; Qu, Z.; Lu, S.; Hu, X.; Ruan, S.; Luo, S.; Wu, J.; Peng, L.; Cheng, F.; Pan, L.; Zou, J.; Jia, C.; Wang, J.; Liu, X.; Wang, S.; Wu, X.; Ge, Q.; He, J.; Zhan, H.; Qiu, F.; Guo, L.; Huang, C.; Jaki, T.; Hayden, F. G.; Horby, P. W.; Zhang, D.; Wang, C., A Trial of Lopinavir-Ritonavir in Adults Hospitalized with Severe Covid-19. New England Journal of Medicine 2020.

22. Johnson, J. P. C. o. J., Lack of evidence to support use of darunavir-based treatments for SARS-CoV-2. 2020.

23. Prabakaran, P.; Xiao, X.; Dimitrov, D. S., A model of the ACE2 structure and function as a SARS-CoV receptor. Biochem Biophys Res Commun 2004, 314 (1), 235-41.

24. Li, W.; Zhang, C.; Sui, J.; Kuhn, J. H.; Moore, M. J.; Luo, S.; Wong, S.-K.; Huang, I.-C.; Xu, K.; Vasilieva, N.; Murakami, A.; He, Y.; Marasco, W. A.; Guan, Y.; Choe, H.; Farzan, M., Receptor and viral determinants of SARS-coronavirus adaptation to human ACE2. The EMBO Journal 2005, 24 (8), 1634-1643.

25. Lu, R.; Zhao, X.; Li, J.; Niu, P.; Yang, B.; Wu, H.; Wang, W.; Song, H.; Huang, B.; Zhu, N.; Bi, Y.; Ma, X.; Zhan, F.; Wang, L.; Hu, T.; Zhou, H.; Hu, Z.; Zhou, W.; Zhao, L.; Chen, J.; Meng, Y.; Wang, J.; Lin, Y.; Yuan, J.; Xie, Z.; Ma, J.; Liu, W. J.; Wang, D.; Xu, W.; Holmes, E. C.; Gao, G. F.; Wu, G.; Chen, W.; Shi, W.; Tan, W., Genomic characterisation and epidemiology of 2019 novel coronavirus: implications for virus origins and receptor binding. The Lancet 2020, 395 (10224), 565-574.

26. Wan, Y.; Shang, J.; Graham, R.; Baric, R. S.; Li, F., Receptor Recognition by the Novel Coronavirus from Wuhan: an Analysis Based on Decade-Long Structural Studies of SARS Coronavirus. Journal of Virology 2020, 94 (7), e00127-20.

27. Hoffmann, M.; Kleine-Weber, H.; Krüger, N.; Müller, M.; Drosten, C.; Pöhlmann, S., The novel coronavirus 2019 (2019-nCoV) uses the SARS-coronavirus receptor ACE2 and the cellular protease TMPRSS2 for entry into target cells. bioRxiv 2020, 2020.01.31.929042.

28. Wrapp, D.; Wang, N.; Corbett, K. S.; Goldsmith, J. A.; Hsieh, C.-L.; Abiona, O.; Graham, B. S.; McLellan, J. S., Cryo-EM structure of the 2019-nCoV spike in the prefusion conformation. Science 2020, 367 (6483), 1260

29. Micholas, S.; Jeremy C., S., Repurposing Therapeutics for COVID-19: Supercomputer-Based Docking to the SARS-CoV-2 Viral Spike Protein and Viral Spike Protein-Human ACE2 Interface. ChemRxiv 2020.

30. Jin, Z.; Du, X.; Xu, Y.; Deng, Y.; Liu, M.; Zhao, Y.; Zhang, B.; Li, X.; Zhang, L.; Peng, C.; Duan, Y.; Yu, J.; Wang, L.; Yang, K.; Liu, F.; Jiang, R.; Yang, X.; You, T.; Liu, X.; Yang, X.; Bai, F.; Liu, H.; Liu, X.; Guddat, L. W.; Xu, W.; Xiao, G.; Qin, C.; Shi, Z.; Jiang, H.; Rao, Z.; Yang, H., Structure of Mpro from COVID-19 virus and discovery of its inhibitors. bioRxiv 2020, 2020.02.26.964882.

31. Lan, J.; Ge, J.; Yu, J.; Shan, S.; Zhou, H.; Fan, S.; Zhang, Q.; Shi, X.; Wang, Q.; Zhang, L.; Wang, X., Structure of the SARSCoV-2 spike receptor-binding domain bound to the ACE2 receptor. Nature 2020. 